\title{
Migration-associated secretion of melanoma inhibitory activity at the cell rear is supported by KCa3.1 potassium channels
}

\author{
Jennifer Schmidt $^{1}$, Kristin Friebel ${ }^{2}$, Roland Schönherr ${ }^{2}$, Marc G Coppolino ${ }^{3}$, Anja-Katrin Bosserhoff ${ }^{1}$ \\ ${ }^{1}$ Institute of Pathology, University of Regensburg, Franz-Josef-Strauss-Allee 11, D-93053 Regensburg, Germany; ${ }^{2}$ Center for Mo- \\ lecular Biomedicine, University of Jena, Germany; ${ }^{3}$ Department of Molecular and Cellular Biology, University of Guelph, Canada
}

Malignant melanoma, characterized by invasive local growth and early formation of metastases, is the most aggressive type of skin cancer. Melanoma inhibitory activity (MIA), secreted by malignant melanoma cells, interacts with the cell adhesion receptors, integrins $\alpha_{4} \beta_{1}$ and $\alpha_{5} \beta_{1}$, facilitating cell detachment and promoting formation of metastases. In the present study, we demonstrate that MIA secretion is confined to the rear end of migrating cells, while in non-migrating cells MIA accumulates in the actin cortex. MIA protein takes a conventional secretory pathway including coat protein complex I (COPI)- and coat protein complex II (COPII)-dependent protein transport to the cell periphery, where its final release depends on intracellular $\mathrm{Ca}^{2+}$ ions. Interestingly, the $\mathrm{Ca}^{2+}$-activated $\mathrm{K}^{+}$-channel, subfamily N, member 4 (KCa3.1), known to be active at the rear end of migrating cells, was found to support MIA secretion. Secretion was diminished by the specific KCa3.1 channel inhibitor TRAM-34 and by expression of dominantnegative mutants of the channel. In summary, we have elucidated the migration-associated transport of MIA protein to the cell rear and also disclosed a new mechanism by which KCa3.1 potassium channels promote cell migration.

Keywords: MIA protein; KCa3.1 potassium channel; migration; directed transport; regulated secretion

Cell Research (2010) 20:1224-1238. doi:10.1038/cr.2010.121; published online 24 August 2010

\section{Introduction}

Previously, MIA has been identified as an $11 \mathrm{kDa}$ protein physiologically produced by cartilage and strongly expressed and secreted by malignant melanoma cells [1, 2]. MIA protein is known to play a key role in melanoma development, progression and formation of metastasis $[2,3]$. Increased MIA protein plasma levels directly correlate with progressive malignancy and a more advanced state of melanocytic tumors [1,4]. Thus, MIA protein serves as a reliable clinical tumor marker to detect and

Correspondence: Anja-Katrin Bosserhoff

Tel: +49-941-944-6705; Fax: +49-941-944-6602

E-mail: anja.bosserhoff@klinik.uni-regensburg.de

Abbreviations: COPI (coat protein complex I); COPII (coat protein complex II); DMEM (Dulbecco's modified Eagle's medium); $\mathrm{KCa} 3.1\left(\mathrm{Ca}^{2+}\right.$ activated $\mathrm{K}^{+}$-channel, subfamily $\mathrm{N}$, member 4); MIA (melanoma inhibitory activity); MTOC (microtubule organizing center); SNARE (soluble Nethylmaleimide-sensitive factor attachment receptor)

Received 25 February 2010; revised 11 June 2010; accepted 5 July 2010; published online 24 August 2010 monitor metastatic disease in patients suffering from malignant melanoma $[1,5,6]$. MIA protein strongly contributes to the invasive and migratory potential of melanoma cells and promotes the formation of tumor metastases [2]; however, the mechanistic link between MIA protein and cell motility remains unclear. Recent data describe a direct interaction of MIA protein with cell adhesion receptors, integrin $\alpha_{4} \beta_{1}$ and integrin $\alpha_{5} \beta_{1}$, followed by facilitation of cell detachment [7]. Cell migration requires adhesion to the extracellular matrix to provide traction points and to stabilize protrusions at the cell front. Conversely, retraction of the rear cell end demands the release of adhesion contacts. In line with this assumption, external addition of MIA protein does not support migration but results in unpolarized cell detachment and reduced invasiveness in Boyden chamber assays [2]. To account for the pro-migratory effect of endogenously expressed and secreted MIA protein, we proposed that MIA secretion is directed to the rear end of a migrating cell where it can bind to integrins and thereby promote cell retraction [7]. MIA-integrin complexes are subsequently internalized at 
the rear of the cell [8].

The MIA secretion pathway has not yet been analyzed in detail, but the protein comprises a typical $\mathrm{N}$-terminal ER-signal peptide that is processed during synthesis [9]. In the conventional secretory pathway, protein synthesis at the ER is followed by its translocation to the Golgi apparatus via COPII-coated vesicles. Further, protein sorting in the Golgi depends on the formation of COPIcoated vesicular intermediates, which mediate retrograde movement of components in the Golgi and back to the ER [10] as well as anterograde movements to the cell membrane. Following vesicle tethering, docking and membrane fusion, the cargo proteins are released into the extracellular space. The final release can either be a constitutive process or a triggered event that depends on an increase in intracellular $\mathrm{Ca}^{2+}$ concentration. Both scenarios involve soluble $\mathrm{N}$-ethylmaleimide-sensitive factor attachment receptor (SNARE) protein complexes to mediate vesicle docking and fusion [11].

Intracellular $\mathrm{Ca}^{2+}$ plays a crucial role in almost all cellular processes, including regulation of membrane fusion as well as cell migration $[12,13]$. By modulating turnover of actin filaments [14-16], activation of calpain [17] and recycling of integrins, $\mathrm{Ca}^{2+}$ coordinates different components of the cellular migration machinery. Another player linking intracellular $\mathrm{Ca}^{2+}$ ions and cell migration is the calcium-activated potassium channel $\mathrm{KCa} 3.1$. This channel type was found to be aberrantly expressed in various tumor types and implicated in the promotion of cell migration and cell proliferation [18-21]. In migrating cells, KCa3.1 channel activity was detected predominantly at the rear cell pole [22], which may be due to the intracellular $\mathrm{Ca}^{2+}$ gradient in polarized, migrating cells. While it was shown that specific inhibition of KCa3.1 channels reduces cell migration [23-25], the underlying mechanisms are still largely elusive.

Here, we used a HisTag-labeled MIA protein construct to monitor MIA secretion in melanoma cells. We show that in migrating cells, MIA secretion is restricted to the rear of the cell. This could be crucial for the mechanism through which MIA contributes to the migration. Experiments using specific inhibitors and dominant negative mutants revealed that MIA follows a conventional secretion pathway, involving COPI- and COPII-dependent protein transport to the cell periphery, where the final release depends on intracellular $\mathrm{Ca}^{2+}$ ions. Further, we show that secretion of MIA protein is significantly augmented by KCa3.1 potassium channel activity. In summary, we provide experimental evidence for our model, first hypothesized in 2006 [7], of facilitated retraction at the rear of migrating cells controlled in part by directed secretion of MIA protein.

\section{Results}

Targeted MIA protein transport to the rear of migrating cells

We aimed to elucidate the MIA protein secretion pathway to further understand the contribution of MIA protein to the enhanced migratory ability of melanoma cells. To follow MIA protein transport and distribution in migrating and non-migrating cells, we visualized MIA protein after transient transfection of Mel Im cells with a His-tagged MIA protein expression plasmid. The MIAHisTag conjugate was visualized in immunofluorescence studies using primary anti-HisTag and fluorescently labeled secondary antibodies. To verify the direction of migration, we co-stained the Golgi apparatus, since it is generally known that in migrating cells, reorientation of the microtubule organizing center (MTOC) repositions the Golgi apparatus toward the leading edge of the cell and contributes to directional cell migration [26]. Figure $1 \mathrm{~A}$ presents Mel Im cells that were cotransfected with pCMX-PL1-hMIA-HisTag and Golgi-GFP (endomannosidase) plasmids to monitor intracellular MIA protein distribution. In polarized migrating cells, MIA protein was asymmetrically distributed at one cell pole as shown in Figure 1A, a. Inferring from the localization of the Golgi on the side of the nucleus towards the leading edge in migrating cells (Figure 1A, b), we conclude that MIA protein is transported to the rear cell pole (Figure 1A, c). Compared to migrating cells, non-polarized and nonmigrating cells showed a homogeneous distribution of MIA protein in the cytoplasm, as illustrated in Figure 1B. Interestingly, MIA protein appeared to accumulate in the actin cortex, possibly in a vesicle pool, as shown in Figure 1B, b and d using the two melanoma cell lines Mel Im and Mel Ju. To further analyze the involvement of the actin cytoskeleton in the secretion of MIA protein, we tested the effect of Jasplakinolide, which induces actin polymerization. Exposure of cells to $5 \mathrm{nM}$ and $50 \mathrm{nM}$ Jasplakinolide resulted in a decrease of about $20 \%$ to $30 \%$ in the amount of secreted MIA protein, respectively, compared to the corresponding DMSO control (data not shown). These observations indicate the involvement of the actin network in MIA protein transport towards the cell rear.

Intracellular transport of MIA protein follows the conventional secretory pathway

To characterize the MIA protein secretion pathway more closely, we analyzed whether MIA protein is transported through the conventional secretory pathway or whether it takes an unconventional route to the cell surface in a Golgi-independent manner. Cells were treated 
A

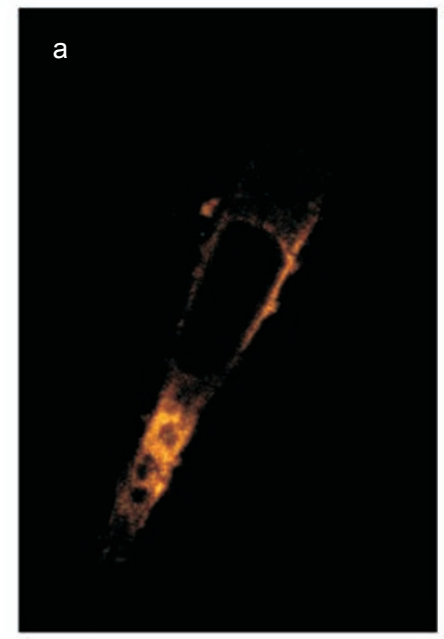

MIA HisTag

B

Mel Ju
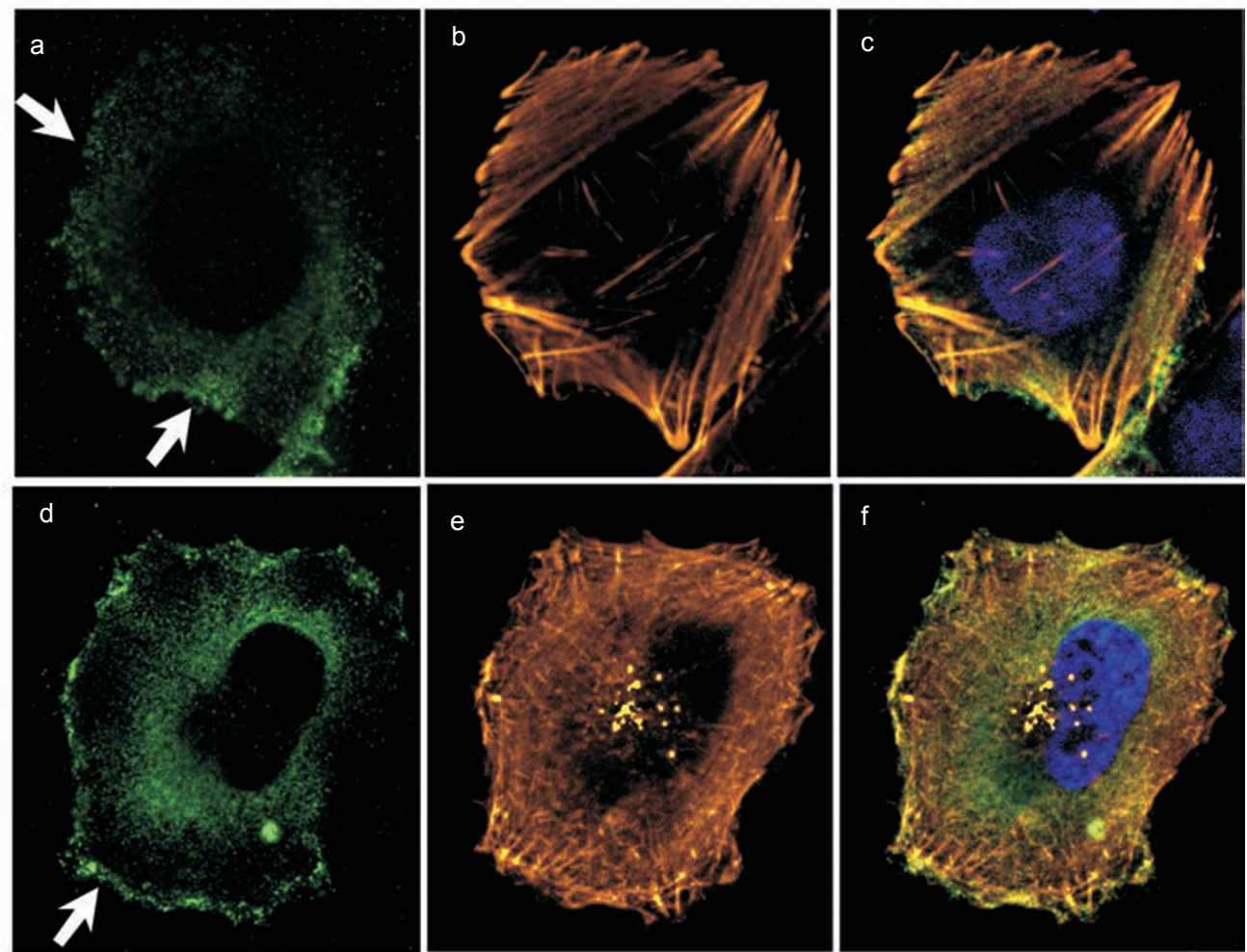

MIA HisTag

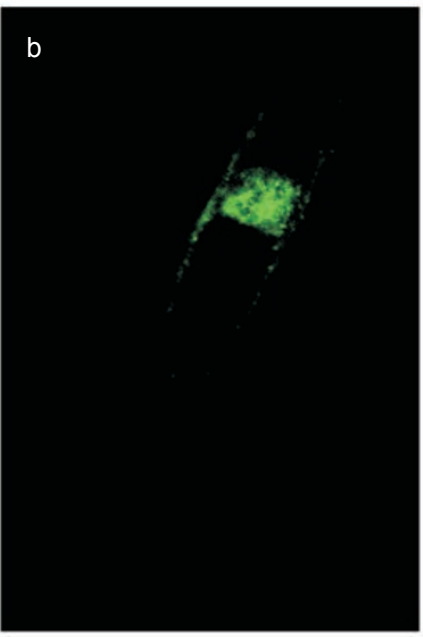

Golgi-GFP

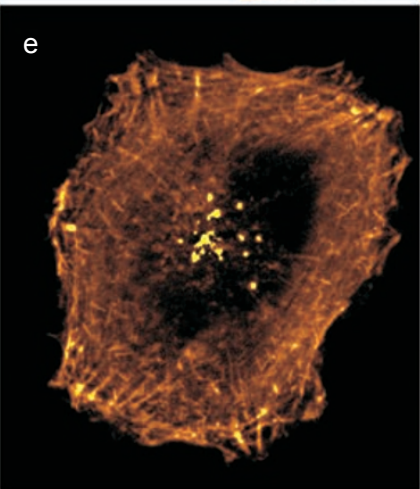

Actin

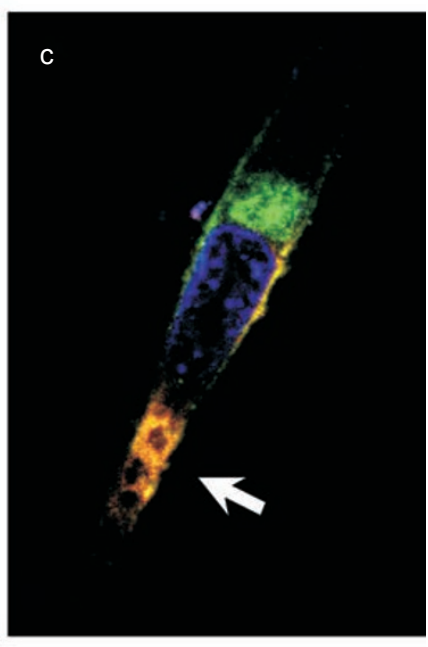

Merge

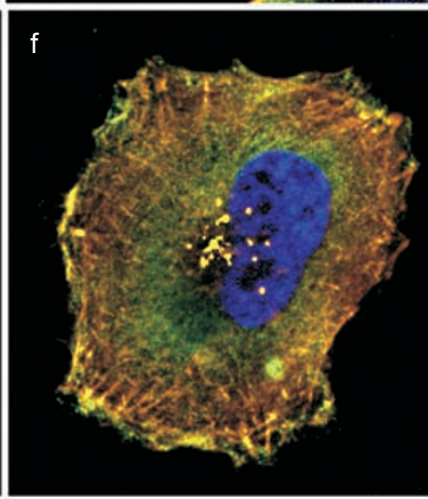

Merge

Figure 1 Targeted MIA protein transport to the cell rear in migrating cells. (A) Mel Im cells were cotransfected with pCMXPL1-hMIA-HisTag and Golgi-GFP (endomannosidase) plasmids to detect intracellular MIA protein distribution and to define direction of movement. In polarized migrating cells, MIA protein was asymmetrically distributed at one cell pole, indicated by the white arrow (a, c). The Golgi apparatus was reoriented toward the leading edge of the cell during migration (b). (c) In migrating cells, MIA protein is transported to the cell rear. (B) Adhered, non-polarized and non-migrating cells transiently transfected with pCMX-PL1-hMIA-HisTag construct showed a homogeneous distribution of MIA protein in the cytoplasm. In the actin cortex, MIA protein accumulated in a vesicle pool as indicated by white arrows in (a) for Mel Im cells and in (d) for Mel Ju cells. All experiments were performed at least in triplicates. 
with the fungal metabolite Brefeldin A, which blocks the recruitment of the ADP-ribosylation factor ARF1 to the Golgi, impairing the formation of COPI-coated vesicles and ultimately inhibiting ER-to-Golgi transport [27]. Cells were also exposed to Exo1, which inhibits the traffic emanating from the ER by inducing rapid collapse of the Golgi into the ER. After cell treatment with these compounds, the MIA protein concentration in cell culture supernatant was determined by MIA-ELISA. The DMSO or $\mathrm{H}_{2} \mathrm{O}$ control was set to $100 \%$. BFA at concentrations of $3.5 \mu \mathrm{M}$ and $7.0 \mu \mathrm{M}$ almost completely inhibited MIA protein secretion in both Mel Im and Mel Ju cells (Figure 2A). Treatment of cells with Exo1 at a concentration of $50 \mu \mathrm{M}$ and $100 \mu \mathrm{M}$ significantly reduced MIA protein secretion. Figure $2 \mathrm{~B}$ presents the corresponding immunofluorescence analysis of the MIA protein. It demonstrates that migrating Mel Im cells, transiently transfected with pCMX-PL1-hMIA-HisTag vector and treated with $7 \mu \mathrm{M}$ BFA, showed an altered distribution of MIA protein. To delineate cell boundaries, the actin cytoskeleton was stained with rhodamine-phalloidin. The control cells showed MIA protein distribution at the cell rear (Figure $2 \mathrm{~B}, \mathrm{a})$. We deduced the direction of cell movement from experiments in which cells were cotransfected with Golgi-GFP (endomannosidase) and the MIA-HisTag construct (Figure 1A, a-c). Almost all cells comprising the characteristic spindle-shaped morphology showed MIA protein staining at the opposite cell pole compared to the MTOC localization. In the overlay of MIA protein and actin filament staining in Figure 2B, c, it is clearly visible that the MIA protein was delivered into the tip of the rear cell edge. After treatment of Mel Im cells with BFA, MIA protein accumulated proximal to the nucleus (Figure 2B, f). Differences in subcellular distribution (subdivided in segment I, II and III) of MIA protein were quantified for each inhibitor as shown in bar chart diagrams in Figure 2B. In comparison to control cells in which about $60 \%$ of the MIA protein-containing vesicles were located in segment II and about $25 \%$ in segment III, in cells treated with BFA the distribution significantly changed $(P<0.01)$; more than $80 \%$ of MIA protein-containing vesicles were retained in segment I, while in segment III hardly any $(<3 \%)$ vesicles were detected.

As a control experiment, we analyzed the effect of BFA treatment on the subcellular distribution of MMP14, a metalloproteinase, which has been described to be strongly expressed in malignant melanoma cells [28]. As previously reported, MMP14 has been found to be mainly transported to the cell front of migrating cells [29]. Immunofluorescence studies shown in Supplementary information, Figure S1A revealed that MMP14 transport was affected by BFA: cells that were exposed to $7 \mu \mathrm{M}$
BFA clearly showed an accumulation of MMP14 in close proximity to the nucleus (d), while in untreated control cells, MMP14 staining was mainly visible at the front membrane of the cell (a), as indicated by white arrows.

In addition, we analyzed the impact of BFA treatment on the subcellular distribution of bFGF in melanoma cells. bFGF, a stimulator of angiogenesis, has been described to be produced and secreted by tumor cells [30]. As reviewed previously [31], bFGF is not transported along the conventional secretion pathway including the endoplasmic reticulum membrane translocation machinery. Thus, we expected BFA not to influence bFGF transport across the cytoplasm of mammalian cells. By immunofluorescence studies, we confirmed that the secretory process of bFGF is not affected by treatment of cells with $7 \mu \mathrm{M}$ BFA (d). We observed a staining pattern identical to the control cells (a) (Supplementary information, Figure S1B).

Cells were also transiently transfected with a dominant negative Sar1p (H79G) construct or mock transfected as controls. Sarlp is a small ER-associated GTPase [3234], necessary for COPII-dependent vesicle formation at the ER [35]. As shown in Figure 2C, overexpression of dominant-negative Sar1p mutant (H79G) led to a reduction of MIA protein secretion relative to mock control, indicating that ER exit of MIA protein is mediated by COPII-coated vesicles.

We further confirmed microtubule-based transport of MIA protein by treatment of melanoma cells with $25 \mu \mathrm{M}$ and $50 \mu \mathrm{M}$ Nocodazole, which leads to depolymerization of microtubules, and $1 \mathrm{mM}$ and $2 \mathrm{mM}$ AMP-PNP, a nonhydrolysable analog of adenosine 5 '-triphosphate which blocks the ATP-dependent microtubule motor protein kinesin [36]. Both compounds reduced MIA protein exocytosis in a dose-dependent manner (Figure 2D). Immunofluorescence analysis of Mel Im cells treated with the kinesin family inhibitor AMP-PNP at a concentration of $2 \mathrm{mM}$ revealed a perturbed distribution of MIA protein: it was delivered to the cell rear, but it was not visible at the rear tip of the cell, suggesting that the peripheral microtubule-based MIA protein transport was interrupted (Figure 2B, i). The quantitative analysis of subcellular distribution further exemplifies this observation. In comparison to BFA-treated cells where most of the MIAcontaining vesicles were located in segment I, in AMPPNP-treated cells most of them $(70 \%)$ were located in segment II.

\section{MIA protein secretion is a $\mathrm{Ca}^{2+}$-regulated process}

It is generally accepted that migrating cells are polarized along their axis of movement and establish an intracellular $\mathrm{Ca}^{2+}$ gradient with a lower $\left[\mathrm{Ca}^{2+}\right]$ at the cell 
A

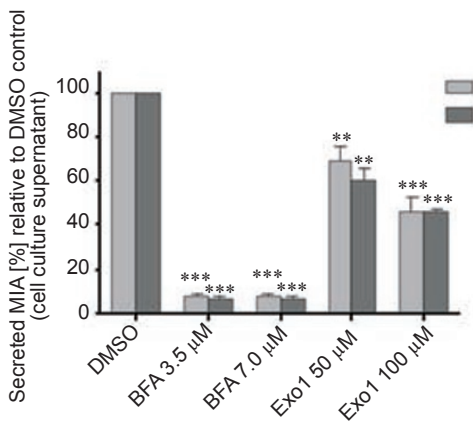

B
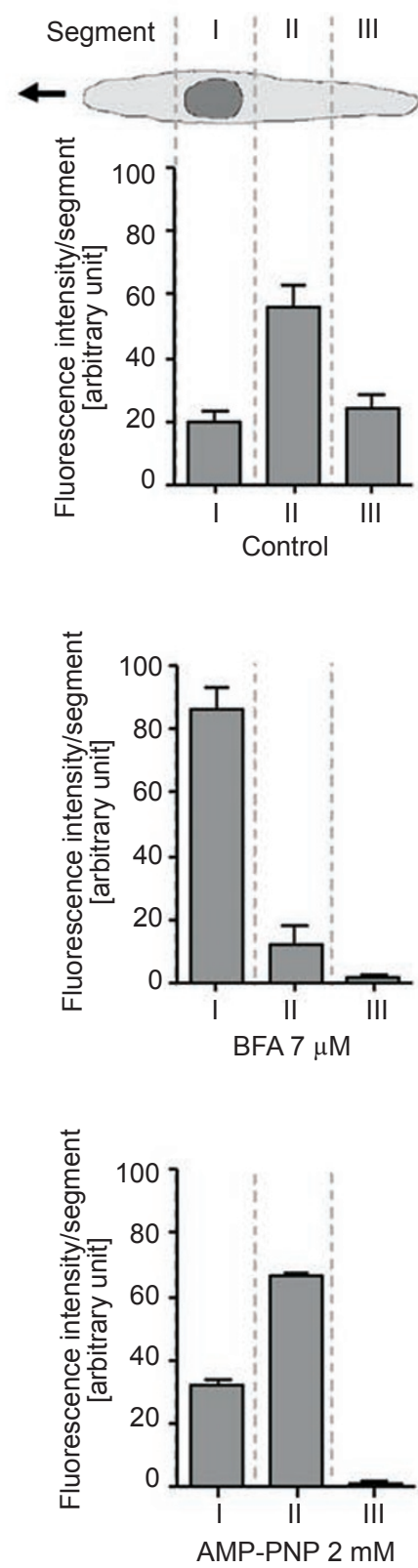

C

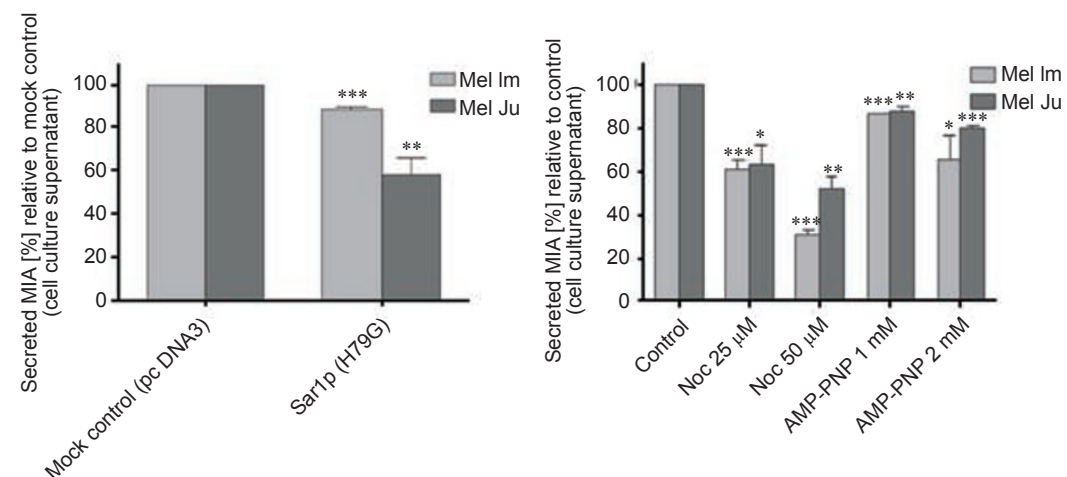

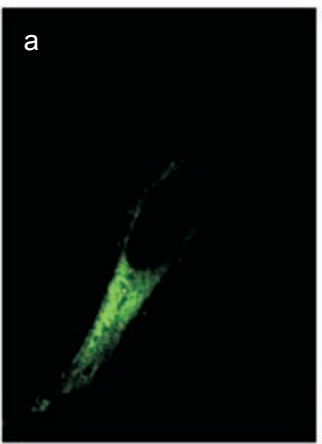
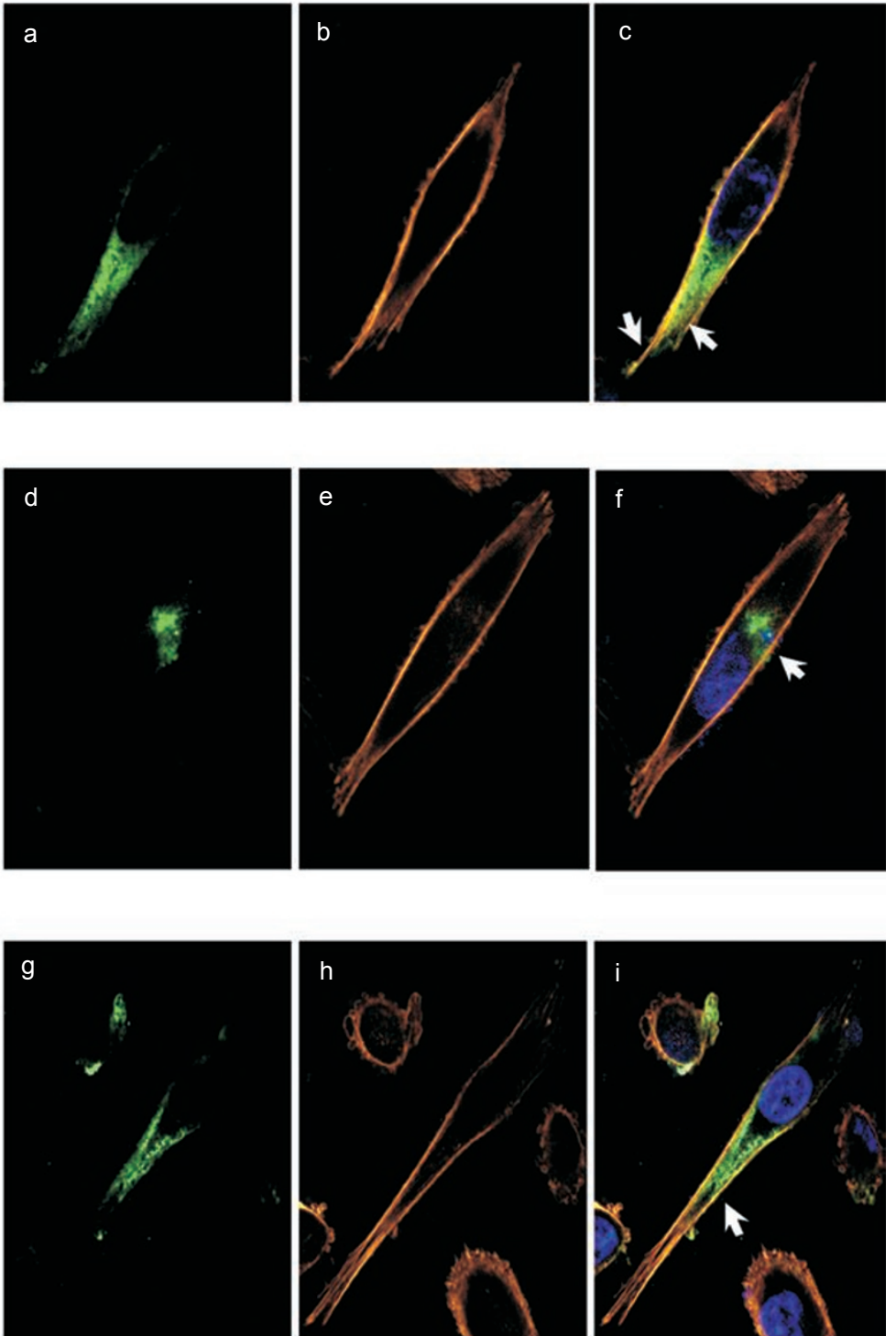

MIA HisTag

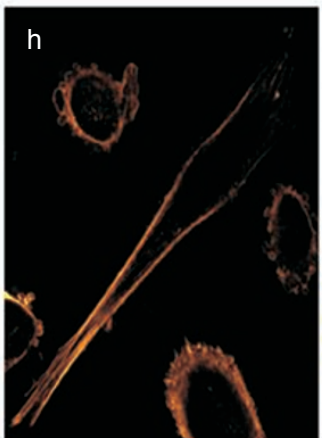

Actin

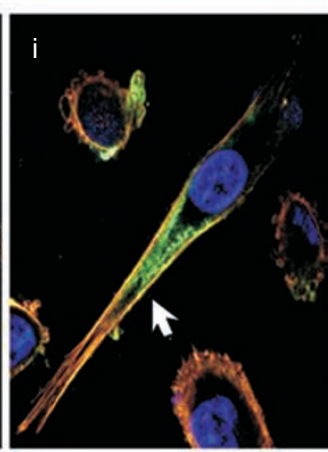

Merge 
Figure 2 ER and Golgi-dependent MIA protein sorting and microtubule-based transport to the rear cell pole. (A) Mel Im cells and Mel Ju cells were treated with BFA and with Exo1, both inhibiting the ER-Golgi transport. BFA at a concentration of 3.5 $\mu \mathrm{M}$ and $7.0 \mu \mathrm{M}$ almost completely inhibited MIA protein secretion in both cell lines. Treatment of cells with Exo1 at a concentration of $50 \mu \mathrm{M}$ and $100 \mu \mathrm{M}$ significantly reduced MIA protein exocytosis compared to the respective $\mathrm{H}_{2} \mathrm{O}$ or DMSO control. (B) Immunofluorescence analysis of Mel Im cells that were transiently transfected with pCMX-PL1-hMIA-HisTag plasmid and stained for MIA protein using a mouse anti-HisTag antibody and a FITC-labeled anti mouse secondary antibody were treated with $7 \mu \mathrm{M}$ BFA and AMP-PNP at a concentration of $2 \mathrm{mM}$. For a better illustration of cell borders, an actin staining was performed in addition. Inhibition of ER-to-Golgi-transport by BFA treatment resulted in an accumulation of MIA protein in close proximity to the nucleus (f). Exposure to AMP-PNP, the vesicle transporter protein inhibitor, led to a characteristic distribution of MIA protein, which is delivered to the cell rear, but it was not visible at the rear tip of the cell since the peripheral microtubule-based MIA protein transport was interrupted (i). In contrast, in the untreated control cells, MIA protein was delivered into the rear cell tip (c), as indicated by the white arrows. Differences in subcellular distribution (subdivided in segment I, II and III) of MIA protein were quantified for each inhibitor as shown in bar chart diagrams. (C) Cells that were transiently transfected with a dominant negative Sar1p (H79G) construct showed a reduction of MIA protein secretion relative to mock control. (D) To investigate microtubule involvement in MIA protein secretion, melanoma cells were treated with $25 \mu \mathrm{M}$ and $50 \mu \mathrm{M}$ Nocodazole, and $1 \mathrm{mM}$ and $2 \mathrm{mM}$ AMP-PNP. Both compounds reduced MIA protein exocytosis in a dose-dependent manner. All experiments were performed at least in triplicates.

front [14-16]. By mediating salt efflux or influx, followed by osmotic water flow, ion channels and transporters play a pivotal role in regulating cell volume during migration. These considerations apply in particular to the $\mathrm{KCa} 3.1$ channel, which is activated in migrating cells by increased $\mathrm{Ca}^{2+}[16,37]$, especially at the cell rear [22]. Since KCa3.1 channel expression was observed in malignant melanoma cells [19], we decided to test for KCa3.1mediated potassium currents in Mel Im cells and to investigate whether there is a direct association of channel activity and MIA protein secretion. Figure 3A showed a typical current response of Mel Im cells to a voltage ramp ranging from $-100 \mathrm{mV}$ to $+50 \mathrm{mV}$ in the wholecell patch clamp configuration. Bath application of the KCa3.1-specific channel blocker TRAM-34 [38] resulted in a rapid decrease of the current amplitude (Figure 3A and $3 \mathrm{~B}$ ), indicating that this channel is, in fact, in an active state. The residual current is most likely due to other ion channels present in this cell line. At least, in part, this remaining current is not carried by potassium-selective channels, as indicated by right-shifted reversal potentials in the presence of TRAM-34.

The above results prompted us to analyze whether inhibition of the KCa3.1 channel by TRAM-34 impacts MIA protein distribution. In the cytoplasm of Mel Im cells that were transiently transfected with His-tagged MIA protein, treatment of migrating cells with TRAM-34 did not prevent the transport of MIA protein to the cell rear. Again, the direction of cell movement was deduced from experiments in which cells were cotransfected with Golgi-GFP (endomannosidase) and the MIA-HisTag construct (Figure 1A, a-c). In these treated cells, however, the MIA protein accumulated at the plasma membrane as shown by white arrows in Figure 3C, f. In the bar chart diagrams, differences of subcellular distribution (divided in segment I and II) of MIA protein were quantified. Treatment of cells with TRAM-34 resulted in a significant $(p<0.05)$ reduction of MIA protein-containing vesicles in segment II. To address the functional impact of KCa3.1 channel activity on MIA protein secretion, we investigated the effects of treatment with activators and inhibitors as well as dominant negative constructs of the KCa3.1 channel. As shown in Figure 4A, activation of the KCa3.1 channel by $100 \mu \mathrm{M}$ and $200 \mu \mathrm{M}$ 1-EBIO led to a small increase in MIA protein secretion, suggesting that these channels are already in the active state. Mel Ju cells, which display a less migratory phenotype compared to Mel Im cells, showed a larger increase in MIA protein secretion after KCa3.1 channel activation. Inhibition of the KCa3.1 channel either by treatment with TRAM-34 at concentrations of $20 \mu \mathrm{M}$ and $40 \mu \mathrm{M}$ or after transfection with two different dominant negative mutant forms of the KCa3.1 channel, dnKCa3.1 Y253L and dnKCa3.1 AAA [39], significantly decreased MIA protein secretion (Figure 4A and $4 \mathrm{~B}$ ). The dominant negative $\mathrm{KCa} 3.1$ constructs encode channel subunits with mutations in the potassium selectivity filter. Upon tetrameric coassembly with wild-type subunits, they generate nonfunctional channels. To confirm the dominant negative activity of the mutant KCa3.1 constructs, HEK293 cells were transfected with the wild-type expression construct alone, or in combination with increasing amounts of dominant negative $\mathrm{KCa} 3.1$ constructs (Figure 4C and 4D). Both dnKCa3.1 constructs decreased the mean potassium currents by at least 70 -fold upon transfection in 4:1 ratio to wild-type KCa3.1. Mock-transfected HEK293 cells did not exhibit any calcium-activated potassium currents (data not shown). To further assess the direct association between MIA protein secretion and expression of the KCa3.1 channel, we transiently cotransfected HEK293 
A

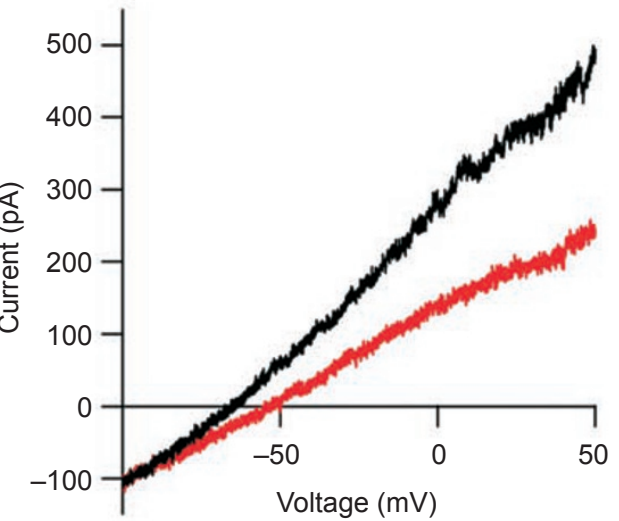

C
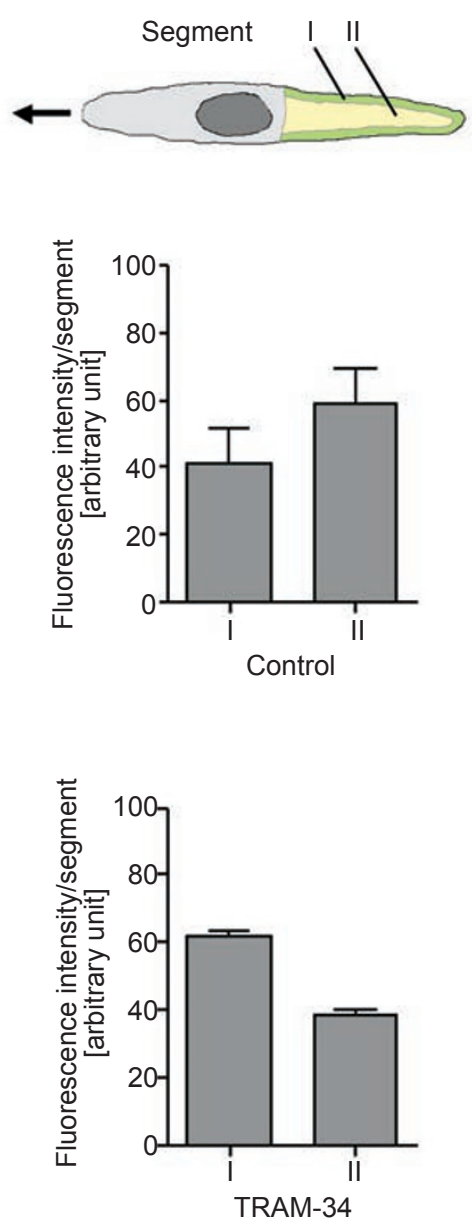

B

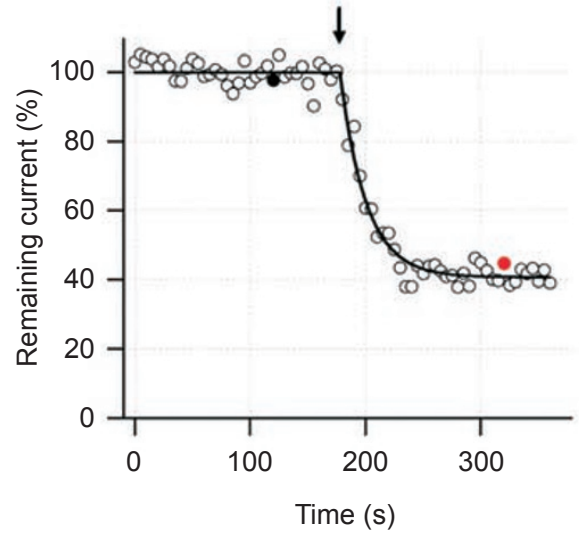

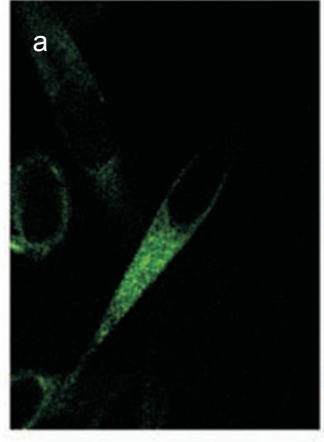
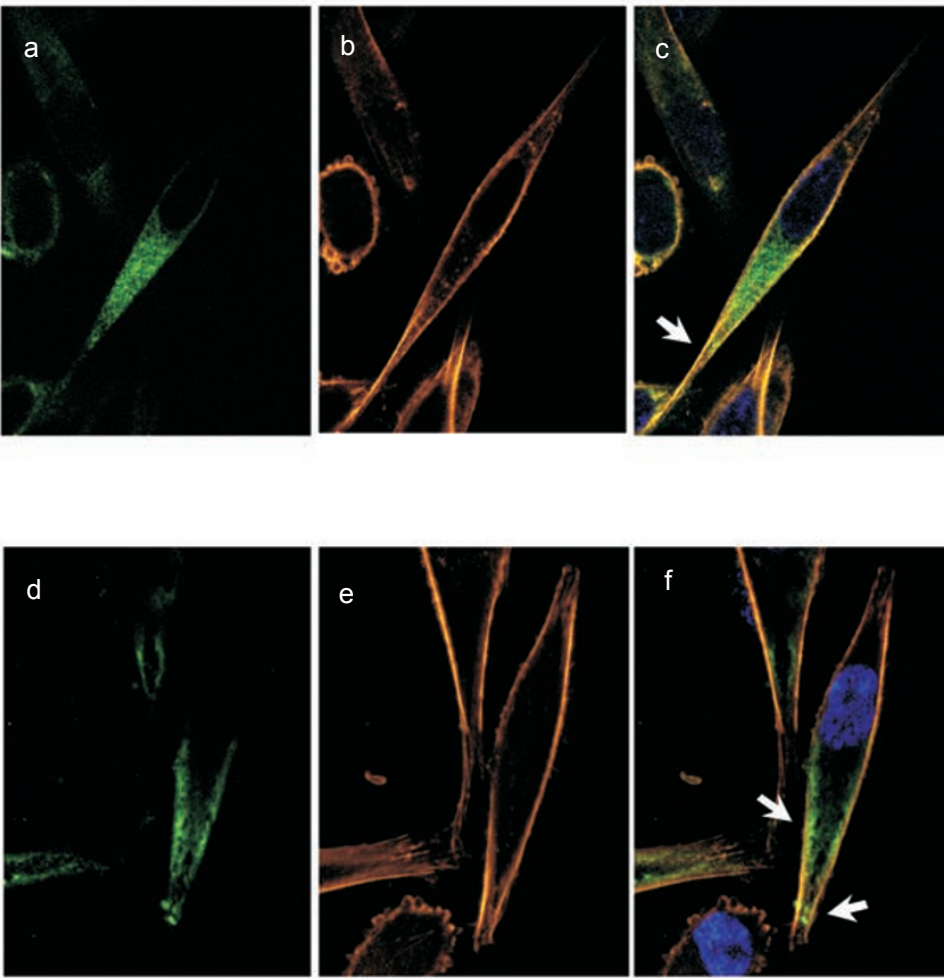

MIA HisTag

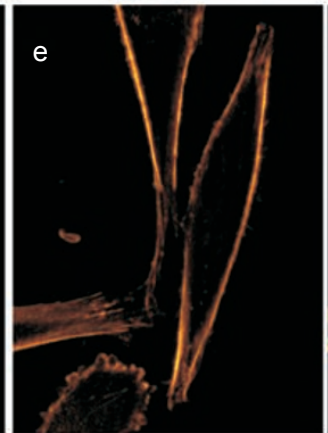

Actin

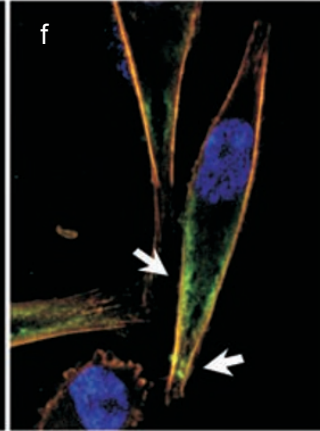

Merge

Figure 3 MIA protein secretion is a $\mathrm{Ca}^{2+}$-regulated process. (A) Verification of active KCa3.1 channels in Mel Im cells. Representative current traces in response to voltage ramps from $-100 \mathrm{mV}$ to $+50 \mathrm{mV}$, recorded before (black) and after (red) application of $200 \mathrm{nM}$ TRAM-34. (B) Time course of KCa3.1 inhibition by TRAM-34. The percentage of remaining current is plotted as a function of time. The start of TRAM-34 application is indicated by the arrow. The continuous line describes the time course of channel block according to a single exponential function. Data points with filled circles correspond to current traces shown in panel B. (C) The corresponding immunofluorescence of Mel Im cells transiently transfected with pCMX-PL1hMIA-HisTag and treated with $40 \mu \mathrm{M}$ TRAM-34 revealed an accumulation of MIA protein at the cell membrane, as indicated by the white arrow (f). In the corresponding control cells (c), MIA protein, transported to the rear cell tip, was homogeneously distributed in the cytoplasm (shown by white arrows). As shown in bar chart diagrams, differences in subcellular distribution (subdivided in segment I and II) of MIA protein were quantified for each inhibitor. Experiments were performed at least in triplicates. 
A

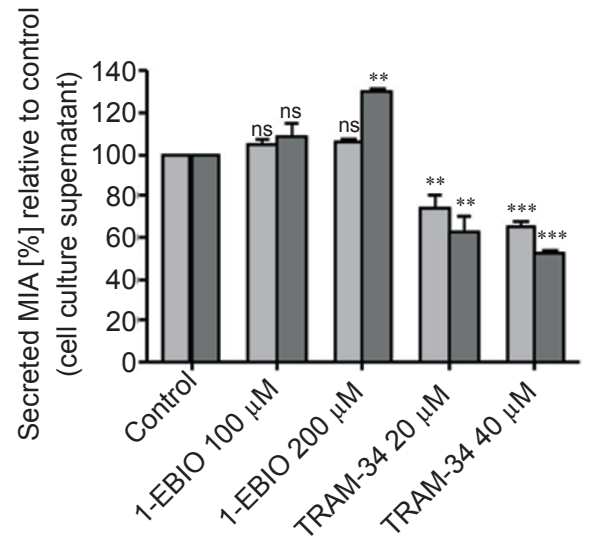

C

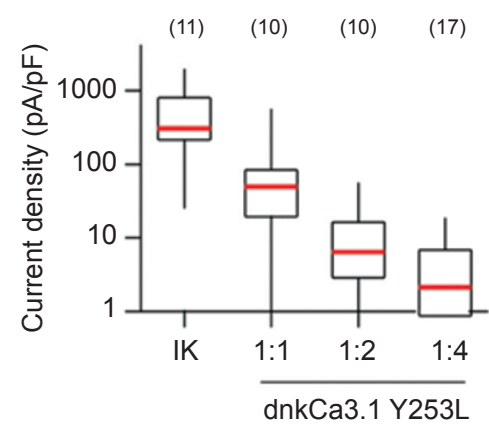

E

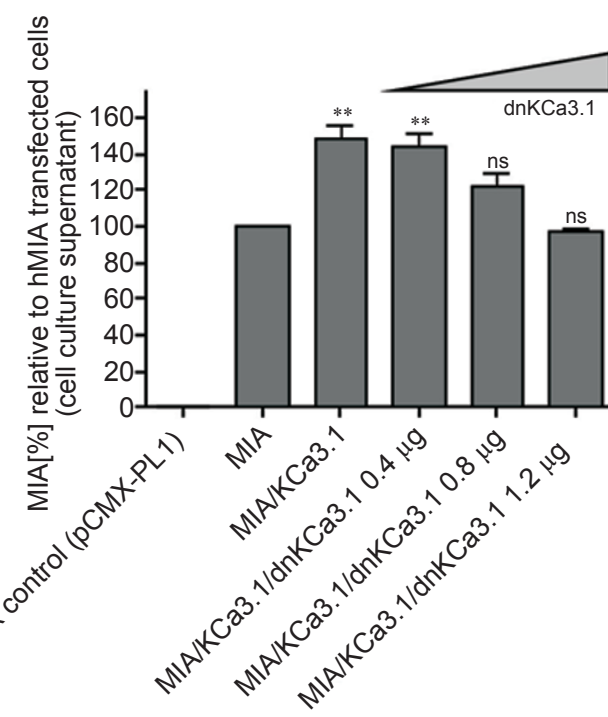

G

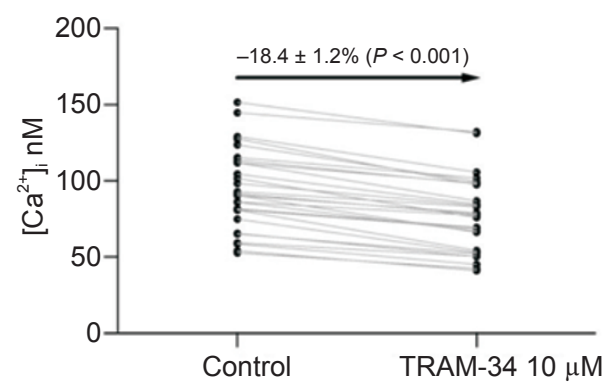

B

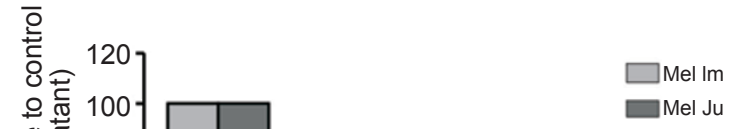

$\square$ Mel Ju

Mel Ju

D

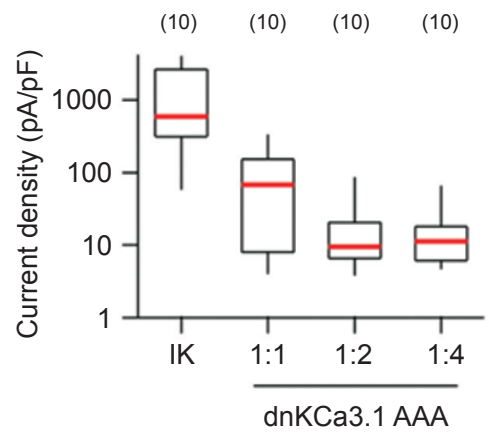

F

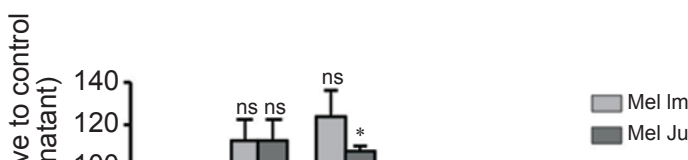

$\mathrm{H}$

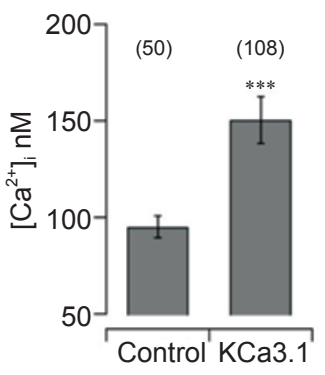


Figure 4 MIA protein secretion is associated to KCa3.1 channel activity. (A) Mel Im and Mel Ju cells were treated with 100 $\mu \mathrm{M}$ and $200 \mu \mathrm{M}$ 1-EBIO, a KCa3.1 channel activator, and with $20 \mu \mathrm{M}$ and $40 \mu \mathrm{M}$ TRAM-34, a specific inhibitor of the KCa3.1 channel. Activation of the KCa3.1 channel by $1-\mathrm{EBIO}$ resulted in a small increase in MIA protein secretion suggesting that the KCa3.1 channel is already in active state. Inhibition of the KCa3.1 channel by TRAM-34 led to significant reduction in MIA protein secretion. (B) Mel Im and Mel Ju cells were transiently transfected with two different dominant negative mutant forms of the KCa3.1 channel, dnKCa3.1 Y253L and dnKCa3.1 AAA. Compared to the mock, control treated cells showed a significant reduction in MIA protein secretion in both cases. (C, D) Verification of dominant negative activity of dnKCa3.1 Y253L (C) and dnKCa3.1 AAA (D). HEK293 cells were transfected with the wild-type KCa3.1 expression construct alone (IK), or in combination with increasing amounts of dominant negative constructs. Current densities are presented as box and whisker plots. Medians are indicated in red. Boxes range from $25-75 \%$ of all data points. Whiskers indicate the lowest and highest current densities. The numbers of individual experiments are indicated in parenthesis. (E) To better demonstrate the direct association of MIA protein secretion and the expression of the KCa3.1 channel, HEK293 cells, which normally neither express MIA protein nor KCa3.1 channels, were transiently cotransfected with pCMX-PL1-hMIA, a KCa3.1 channel-containing plasmid and the dominant negative construct of the KCa3.1 channel dnKCa3.1 AAA with different vector amounts. Cotransfection of MIA and KCa3.1 vectors led to an increase in MIA protein secretion by about $40 \%$ relative to MIA protein exocytosis of cells, which were transfected with a MIA vector PCMX-PL1-hMIA alone. This effect can be reduced to the level of the control by cotransfection of cells with dnKCa3.1 AAA, the mutant form of the KCa3.1 channel, in a dose-dependent manner. (F) The influence of intracellular $\mathrm{Ca}^{2+}$ concentration on MIA protein secretion was investigated by exposure of Mel Im and Mel Ju cells to $1 \mathrm{nM}$ and $10 \mathrm{nM}$ calcimycin (A23187), and $1 \mu \mathrm{M}$ and $5 \mu \mathrm{M}$ BAPTA-AM. Relative to cell culture supernatant from DMSOtreated control cells, the secreted MIA protein amount increased up to $120 \%$ after calcimycin treatment, and exposure to BABTA-AM resulted in a significant decrease in MIA protein secretion. (G) Free intracellular calcium concentrations of Mel Im cells before and after application of $10 \mu \mathrm{M}$ TRAM-34. Cells loaded with Fura-2-AM were continuously perfused with HBSS for at least 5 min until the perfusion was stopped and TRAM-34 $(10 \mu \mathrm{M})$ was applied via a glass pipette. The averaged calcium concentrations for 5-min intervals before and after TRAM-34 application are plotted for 28 cells (black dots) and the decline in the calcium concentration in each cell is indicated by a gray line. The mean calcium decrement is $18.4 \pm 1.2 \%$ (paired $t$-test, $P<0.001)$ ), as indicated above the black arrow. (H) KCa3.1 transfection leads to elevated calcium levels in HEK293 cells. The bar graphs show the mean free intracellular calcium concentration \pm s.e.m. for pcDNA3-transfected controls (50 cells) and KCa3.1-transfected cells (108), $* * * P<0.001$. Experiments were performed in triplicates.

cells (which normally express neither MIA protein nor KCa3.1 channels) with a MIA protein-containing plasmid, pCMX-PL1-hMIA, a KCa3.1 channel-containing plasmid, and the dominant negative $\mathrm{KCa} 3.1$ construct (dnKCa3.1 AAA), using a range of amounts of the different vectors (Figure 4E). Cotransfection of MIA and KCa3.1 vectors increased MIA protein secretion by approximately $40 \%$ relative to cells that were transfected with a MIA vector alone. This effect could be reduced in a dose-dependent manner to the level of the control by cotransfection of cells with dnKCa3.1 AAA, the mutant form of the KCa3.1 channel. This observation clearly shows a direct association of MIA protein secretion and KCa3.1 channel activity.

Since the KCa3.1 channel activity is increased by an elevation in the intracellular $\mathrm{Ca}^{2+}$ concentration, we also examined the influence of $\mathrm{Ca}^{2+}$ on MIA protein secretion. This is of particular interest, since the $\mathrm{Ca}^{2+}$ concentration is elevated at the rear of migrating cells where MIA protein is also secreted. Treatment of cells with $1 \mu \mathrm{M}$ and $5 \mu \mathrm{M}$ BAPTA-AM, a membrane permeable, selective chelator of intracellular $\mathrm{Ca}^{2+}[40]$, led to a significant decrease in MIA protein secretion in a dose-dependent manner (Figure 4F). In addition, we incubated Mel
Im and Mel Ju cells with $1 \mathrm{nM}$ and $10 \mathrm{nM}$ calcimycin (A23187), an ionophore that is highly selective for $\mathrm{Ca}^{2+}$ ions, leading to an elevation in the intracellular $\mathrm{Ca}^{2+}$ concentration [41]. Interestingly, the amount of MIA protein secreted into the cell culture supernatant increased by $20 \%$ compared to DMSO-treated control cells. All these results strongly argue for a $\mathrm{KCa} 3.1$ channel-associated regulation of MIA protein secretion.

To further support our results, we analyzed the effect of KCa3.1 activator 1-EBIO and inhibitor TRAM-34 in BAPTA-AM-treated Mel Im and Mel Ju melanoma cells. Here, cells were treated with $5 \mu \mathrm{M}$ BAPTA-AM and simultaneously exposed to $100 \mu \mathrm{M} 1$-EBIO or $20 \mu \mathrm{M}$ TRAM-34. The experimental conditions chosen for these analyses were exactly the same as described for the MIA secretion assay. The MIA protein concentration in cell culture supernatant was determined by MIA-ELISA. As shown in Supplementary information, Figure S2A, the amount of secreted MIA protein was drastically reduced by about $80 \%$ compared to the control after BAPTA-AM treatment. Addition of 1-EBIO and TRAM-34 did not significantly alter MIA protein secretion in comparison to cells exposed to BAPTA-AM.

To extend these investigations to cell migration, 
Boyden chamber migration experiments using identical experimental conditions and concentrations of inhibitors and activators as for the MIA protein secretion assay described above were performed with Mel Im and Mel $\mathrm{Ju}$ cells, respectively. With this assay comparable results were observed: treatment of cells with BAPTA-AM led to a reduction in the number of migrated cells compared to the untreated control cells by about $35 \%$ to $40 \%$ for both cell lines. Further addition of channel activator 1-EBIO and inhibitor TRAM-34, respectively, did not affect the number of migrating cells as shown in Supplementary information, Figure S2B. The finding that effects of KCa3.1 channels on both MIA secretion and cell migration are abolished in BAPTA-treated cells suggests that $\mathrm{KCa} 3.1$ modulates both processes via an increase in the cytosolic $\mathrm{Ca}^{2+}$ concentration. We performed calcium imaging experiments to address this directly. As shown in Figure 4G, the basal level of intracellular calcium in Mel Im cells was heterogeneous, but in all analyzed cells, application of $10 \mu \mathrm{M}$ TRAM-34 resulted in a decrease of $\left[\mathrm{Ca}^{2+}\right]_{i}$, with a highly significant mean reduction of $18.4 \pm 1.2 \%$. On the other hand, expression of KCa3.1 in HEK293 cells induced a significantly higher level of $\left[\mathrm{Ca}^{2+}\right]_{\mathrm{i}}$ compared to a mock transfection (Figure $4 \mathrm{H})$. The mean calcium concentration in control cells was $95.1 \pm 5.8 \%$, while $\mathrm{KCa} 3.1$-transfected cells had a mean $\left[\mathrm{Ca}^{2+}\right]_{\mathrm{i}}$ of $150.4 \pm 12.1 \%$. Thus, the increased MIA secretion in HEK23 cells upon KC3.1 expression can be attributed to increased intracellular calcium levels.

\section{Discussion}

In the present study, we elucidated the secretory pathway of MIA protein, which was previously identified to play a key role in the formation of metastases in malignant melanoma. MIA protein was described to directly interact with cell adhesion receptors, integrin $\alpha_{4} \beta_{1}$ and integrin $\alpha_{5} \beta_{1}$ [7], as well as with extracellular matrix molecules including fibronectin, tenascin and laminin [2]. As a result, matrix structures surrounding the cell and integrin adhesion molecules are masked by MIA protein, which consequently impacts melanoma cell attachment. Thus, we proposed that the contribution of MIA protein to the enhanced invasive capacity of malignant melanoma cells can be ascribed to a mechanism requiring targeted MIA protein transport and secretion. To enable a tumor cell to migrate in a defined direction, localized cell detachment is a prerequisite and could be achieved by directed MIA protein transport to the cell rear followed by localized MIA protein exocytosis. Based on this proposal, we have now investigated the secretion pathway of MIA protein and for the first time, we describe a targeted, migration- associated transport of a secretory protein to the rear cell pole.

Induction of cell migration triggers the directed MIA protein delivery to the rear cell pole

Non-polarized and non-migrating cells show a homogeneous distribution of MIA protein in the cytoplasm. After external stimuli, the initial response of a cell is to polarize, meaning that molecular processes at the cell front differ from that at the cell rear. The cell starts to extend protrusions at the leading edge that are stabilized by adhesion to the extracellular matrix. These adhesion contacts serve as traction points for migration and initiate signals that regulate adhesion dynamics and trailing edge retraction. Dynamic responses that drive migration are dependent on a highly organized cytoskeleton function.

In polarized control cells, we clearly defined the direction of migration by staining both the MIA protein and the Golgi apparatus, which, together with the MTOC, is reoriented toward the leading edge. Thus, we were able to follow MIA protein delivery to the rear cell pole. Generally, migration is initiated in response to extracellular stimuli. Required cell polarity is mediated by a set of interlinked positive feedback loops. Following the increased activity of Rho-family GTPases, integrins form focal adhesions, and subsequently phosphoinositide 3-kinases, microtubules, vesicular transport and other factors are involved [42]. The fine regulation of the actin cytoskeleton presupposes complex control mechanisms to ensure coordinated migration, which can be turned on and off by the cell based on the requirements of a given situation [43]. At this time, the molecular details of the initiation of migration are not completely understood. Upon examining immunofluorescence staining of migrating cells, we deduced that regulation of directed MIA protein transport is critical to the intricate process of migration initiation. The characteristic unidirectional MIA protein distribution is clearly visible, even if the MIA protein transport is perturbed by treatment with AMPPNP or TRAM-34. This observation of specifically targeted MIA protein secretion agrees well with data established in previous studies [8] that demonstrate an uptake of MIA protein-integrin complexes at the cell rear of migrating cells, and thus strongly supports our hypothesis.

Our findings suggest that exocytic vesicles containing MIA protein take the conventional secretory pathway to the cell exterior. MIA contains an amino-terminal signal peptide that directs its translation into the ER. Afterwards, it is transported through the ER-Golgi pathway of protein export involving COPI- and COPII-coated vesicles. Mediated by the motor protein kinesin, MIA protein-containing secretory vesicles are transported 
along the microtubule system. After transport through the dense meshwork of actin filaments, MIA protein reaches the plasma membrane at the cell rear where it is finally exocytosed.

MIA protein secretion is a $\mathrm{Ca}^{2+}$-regulated process and is directly associated with KCa3.1 channel activity

We determined that MIA protein secretion is a $\mathrm{Ca}^{2+}$ regulated process, similar to the previously described secretion of many other specialized exocytic vesicles such as azurophile granules in neutrophils [44], specific granules in mast cells [45] and lytic granules in cytotoxic Tlymphocytes $[46,47]$. The most thoroughly characterized $\mathrm{Ca}^{2+}$-triggered exocytosis is the release of neurotransmitters into the synaptic space [48]. Elevation in intracellular $\mathrm{Ca}^{2+}$ levels induces vesicle docking and fusion events at the plasma membrane mediated by SNARE proteins. In addition to these fusion events, several other factors involved at different stages of the secretory pathway are reported to be potential $\mathrm{Ca}^{2+}$ targets during the regulation of neurotransmitter release, e.g., protein kinases [49] as well as other $\mathrm{Ca}^{2+}$-regulated proteins like rabphilin, $\alpha$-actinin [50] and $\beta$-adductin [51], which are involved in the regulation of actin filament organization. Here, we show that in the meshwork of actin filaments, a pool of MIA protein-containing secretory vesicles is stored and is only visible in adherent, non-migrating melanoma cells. Interestingly, intracellular $\mathrm{Ca}^{2+}$ has also been found to be responsible for the recovery of the storage pool following neurotransmitter release [52].

Intracellular $\mathrm{Ca}^{2+}$ plays a fundamental role in regulating cellular events and signaling. Cell migration is a process that strongly depends on intracellular $\mathrm{Ca}^{2+}$, including the influences that $\mathrm{Ca}^{2+}$ has on volume-regulating mechanisms. Cell volume, which is subjected to fluctuations that are related to permanent cell shape changes, increases during protrusion of the lamellopodium at the cell front $[53,54]$ and decreases during retraction of the rear cell body. In addition to setting the cell volume, intracellular $\mathrm{Ca}^{2+}$ modulates the turnover of actin filaments; an elevation of $\mathrm{Ca}^{2+}$ promotes actin depolymerization, whereas a low $\mathrm{Ca}^{2+}$ concentration favors actin polymerization. The regulation of the cytoskeletal migration machinery is supported by the intracellular gradient of $\mathrm{Ca}^{2+}$ with the higher concentration at the cell rear [1416]. Another relevant factor for the motility of cells is the $\mathrm{Ca}^{2+}$-controlled function of calpains in the release of cell-extracellular matrix contacts [17] at the cell rear. Subsequently, this release is then followed by the recycling of integrins [55]. Further, the contraction of the rear cell body by $\mathrm{Ca}^{2+}$-regulated phosphorylation of myosin light chain is an important step during migration [56].
The close relationship between intracellular $\mathrm{Ca}^{2+}$ ion concentration and cell migration-promoting processes strongly suggests a crucial role for ion channel activity. Since $\mathrm{Ca}^{2+}$-activated $\mathrm{K}^{+}$channels are expressed in most (if not all) cells possessing the ability to migrate, including leukocytes and many tumor cells, their roles in cell migration warrant close examination [18, 57-63]. In previous studies, it was described that the $\mathrm{KCa} 3.1$ channel is highly expressed in malignant melanoma cells [19]. Ion fluctuations mediated by the $\mathrm{KCa} 3.1$ channel are known to play a fundamental role in cell migration [23, 64-66], since inhibition with specific blockers or activation of this ion channel results in impaired cell mobility [23, 67]. Interestingly, it was also reported that the $\mathrm{KCa} 3.1$ channels are only active at the rear cell pole of migrating cells due to the intracellular $\mathrm{Ca}^{2+}$ gradient [22]. At the cell front KCa3.1 channels appear to be inactive [66].

The results described here are consistent with the observation of $\mathrm{Ca}^{2+}$-regulated secretion of MIA protein at the cell rear and support a model that underlines the pivotal function of MIA protein in promoting the directed migration. A migratory stimulus leads to elevation in intracellular $\mathrm{Ca}^{2+}$ concentration, which activates the KCa3.1 channel. The channel activity in turn causes hyperpolarization of the cell membrane and thus a higher electrochemical driving force for $\mathrm{Ca}^{2+}$ influx $[21,68]$. Consequently, we found that channel inhibition reduced the intracellular $\mathrm{Ca}^{2+}$ levels, while expression of $\mathrm{KCa} 3.1$ leads to elevated $\mathrm{Ca}^{2+}$ levels in transfected cells. Since these ion channels are mainly active at the cell rear, the increase in intracellular $\mathrm{Ca}^{2+}$ promotes cell migration by several mechanisms mentioned above and simultaneously induces fusion of MIA protein-containing secretory vesicles with the plasma membrane at the rear cell pole. While KCa3.1 activity clearly facilitates MIA secretion, it is not an indispensable prerequisite for the secretion process, neither in melanoma cells nor in transfected HEK293 cells. It is important to mention that our experimental strategies, used to eliminate KCa3.1 function, do not remove the channel complexes, but rather interfere with the pore function. For the voltage-gated potassium channel Kv2.1 (KCNB1) it was recently shown that it facilitates exocytosis in PC12 chromaffin cells by direct interaction with the SNARE protein syntaxin, independently of the functional pore [69]. While a direct interaction of KCa3.1 with the export machinery may not be excluded at this time, its function in MIA exocytosis does require potassium efflux through the channel pore.

Once MIA is exocytosed at the cell rear, it is able to mask extracellular matrix structures and facilitate cell detachment through a direct interaction with cell adhesion receptors, integrin $\alpha_{4} \beta_{1}$ and integrin $\alpha_{5} \beta_{1}$. While at the 
rear pole cell-extracellular matrix contacts are detached followed by internalization of MIA protein-integrin complexes; at the cell front, recycled integrins are exocytosed at the surface, allowing new cell-ECM contacts to form. Thus, migration-associated MIA protein secretion at the cell rear strongly supports the directed cell movement and helps to explain the aggressive migratory behavior and metastatic potential of malignant melanoma cells.

\section{Materials and Methods}

\section{Cell lines and cell culture conditions}

The melanoma cell line Mel Im, established from a human metastatic bioptic sample (generous gift from Dr Johnson, University of Munich, Germany), was used in almost all experiments. In addition, main experiments were also conducted using the human cell line $\mathrm{Mel} \mathrm{Ju}$, which was derived from metastases of malignant melanoma. HEK293 cells were obtained from the German Collection of Microorganisms and Cell Cultures (DSMZ, Braunschweig, Germany). All cells were maintained in DMEM (Dulbecco's modified Eagle's medium; PAA Laboratories GmbH, Austria) supplemented with penicillin $(400 \mathrm{U} / \mathrm{ml})$, streptomycin $(50 \mu \mathrm{g} / \mathrm{ml})$, L-glutamine $(300 \mu \mathrm{g} / \mathrm{ml})$ and $10 \%$ fetal calf serum (Pan Biotech $\mathrm{GmbH}$, Germany) and split in 1:5 ratio every 3 days.

\section{MIA secretion assay}

$2.5 \times 10^{5}$ cells per $\mathrm{ml}$ were seeded in 6-well plates (Corning Omnilab, Germany) and cultured in $2 \mathrm{ml}$ of DMEM (PAA, Germany) with $10 \%$ fetal calf serum (Pan). Cells were treated with various inhibitory compounds (all purchased from Sigma Aldrich, Germany) in different final concentrations: 3-(4-fluorobenzoylamino)benzoic acid methyl ester (Exo1) was used at a final concentration of $50 \mu \mathrm{M}$ and $100 \mu \mathrm{M}$, Brefeldin A (BFA) at $3.5 \mu \mathrm{M}$ and $7 \mu \mathrm{M}$, Nocodazole at $25 \mu \mathrm{M}$ and $50 \mu \mathrm{M}$, Jasplakinolide at $5 \mathrm{nM}$ and 50 $\mathrm{nM}$, adenosine 5 '-( $\beta, \gamma$-imido)triphosphate tetralithium salt hydrate (AMP-PNP) at $1 \mathrm{mM}$ and $2 \mathrm{mM}, 1,2$-bis(2-aminophenoxy)ethane$\mathrm{N}, \mathrm{N}, \mathrm{N}^{\prime}, \mathrm{N}^{\prime}$-tetraacetic acid tetrakis(acetoxymethyl ester) (BAPTA$\mathrm{AM})$ at $1 \mu \mathrm{M}$ and $5 \mu \mathrm{M}$, calcimycin (A23187) at $1 \mathrm{nM}$ and $10 \mathrm{nM}$, 1-ehly-2-benzimidazolinone (1-EBIO) at $100 \mu \mathrm{M}$ and $200 \mu \mathrm{M}$ and 1-[(chlorophenyl)diphenylmethyl]1-H-pyrazole (TRAM-34) was used at a final concentration of $20 \mu \mathrm{M}$ and $40 \mu \mathrm{M}$. Except AMPPNP, which was dissolved in $\mathrm{H}_{2} \mathrm{O}$, all compounds mentioned above were dissolved in DMSO, which was also used in the corresponding control experiment. After treatment, cells were incubated for $8 \mathrm{~h}$ at $37{ }^{\circ} \mathrm{C}$ with $8 \% \mathrm{CO}_{2}$. Afterwards, the cell culture supernatant was collected for quantification of secreted MIA protein using an ELISA system (Roche Applied Science, Germany). Monoclonal antibodies coupled with biotin or peroxidase were used to quantify MIA protein in a 96-well plate coated with streptavidin. 2,2'-azinodi[3-ethylbenzthiazoline sulfonate] (ABTS) was used as substrate and measured at $405 \mathrm{~nm}$ using a fluorescence microplate reader ( $\mathrm{E}_{\max }$ precision microplate reader, Molecular Devices).

\section{MIA-HisTag and dnKCa3.1 plasmid construction}

MIA HisTag expression plasmid was created by PCR amplification of human melanoma cDNA using the MJ Research PTC-200 Peltier Thermo Cycler (BioRad). The cDNA was generated from RNA isolated from the melanoma cell line, Mel Im, using the total
RNA Kit (Omega Biotech, USA) followed by reverse transcription using Superscript (Invitrogen, Germany). The HisTag sequence was inserted between the hydrophobic signal-peptide sequence responsible for transport into the endoplasmic reticulum and the MIA sequence according to the site-directed mutagenesis by overlap extension (SOE)-method [70] using the primers 5'-GAC GAA TTC ATG GCC CGG TCC CTG GTG-3' and 5'-CAT AGG ACC ACC GTG ATG GTG ATG GTG ATG GTG ATG CCT GAC ACC AGG-3' for the signal-peptide HisTag fragment and 5'-CCT GGT GTC AGG CAT CAC CAT CAC CAT CAC CAT CAC GGT GGT CCT ATG-3' and 5'-GAC AAG CTT TCA CTG GCA GTA GAA ATC CCA-3' for amplification of HisTag-MIA fragment. After fusion of these two fragments and digestion of the resulting PCR product with EcoRI and HindIII (New England Biolabs, Germany), this insert was purified by gel extraction (Qiagen, Germany) and cloned into the EcoRI and HindIII sites of the eukaryotic expression vector pCMX-PL1 [71], which was previously purified and prepared for ligation using T4-Ligase (New England Biolabs). After transformation in DH10 $\beta$ cells (New England Biolabs) according to the manufacturer's instructions the plasmids were isolated using the MIDI Kit (Qiagen) and quantified by a gene quant II RNA/DNA Calculator (Pharmacia Biotech). The dnKCa3.1 constructs with amino acid replacements in the selectivity filter of the potassium channel were generated with the QuikChange Mutagenesis kit (Stratagene, Germany). The introduced amino acids are Leu253 (replacing Tyr; dnKCa3.1 Y253L) and Ala252-Ala253Ala254 (replacing Gly-Tyr-Gly; dnKCa3.1 AAA). The sequences of the PCR-generated clones were confirmed by DNA sequencing.

\section{Transient transfection}

For transient transfection, $2 \times 10^{5}$ cells per $\mathrm{ml}$ were seeded in 6-well plates (Corning Omnilab) and cultured in $2 \mathrm{ml}$ of DMEM (PAA) with $10 \%$ fetal calf serum (Pan). Cells were transiently transfected with $1 \mu \mathrm{g}$ of the respective plasmid using the LipofectaminPlus (Invitrogen) method according to the manufacturer's instructions. The transfection efficiency was approximately $45 \%$. To investigate the MIA protein secretion pathway, Mel Im cells and Mel Ju cells were transfected with Sarlp (H79G) mutant (generous gift from Ben Distel, University of Amsterdam, NL) and the respective mock control plasmid pcDNA3. To demonstrate the involvement of the $\mathrm{KCa} 3.1$ channel in regulation of MIA protein secretion, cells were transiently transfected with the expression plasmids KCa3.1 (generous gift from Dr Albrecht Schwab, University of Münster, Germany) and pCMX-PL1 hMIA [71], the dominant negative form dnKCa3.1 AAA or dnKCa3.1 Y253L, and the respective mock control pCMX-PL1 and pcDNA3. At $48 \mathrm{~h}$ after transfection, the cell culture supernatant was collected for quantification of secreted MIA protein using an ELISA system (Roche Applied Science) as described above.

For immunofluorescence staining experiments, $10^{5} \mathrm{Mel}$ Im cells and Mel Ju cells were grown on a 4-well chamber slide (Falcon, BD Biosciences, Germany). Transient transfection and cotransfection of these cells with MIA HisTag and Golgi-GFP (endomannosidase) plasmids (kindly provided by Dr Christof Voelker, University of Bonn, Germany) and the respective mock control was also performed using the LipofectaminPlus (Invitrogen) method according to the manufacturer's instructions. First, cells were transfected with the Golgi-GFP plasmid and incubated for $24 \mathrm{~h}$ before further treatment. During this time span, the reorientation 
of the MTOC, a comparatively slow process that can take several hours after migratory stimuli, is ensured. Afterwards, cells were cotransfected with the MIA HisTag plasmid and the respective mock control pCMX-PL1. After another $24 \mathrm{~h}$, cells were treated with various inhibitory compounds in different final concentrations, fixed and prepared for immunofluorescence microscopy.

\section{Immunofluorescence assays}

A total of $5 \times 10^{5}$ melanoma cells, Mel Im and Mel Ju, and human epithelial kidney cell line, HEK293 cells, were grown in a 4-well chamber slide (Falcon, BD Biosciences). After transient transfection and cotransfection with MIA HisTag and Golgi-GFP plasmids and the respective mock control, cells were treated with BFA at final concentrations of $3.5 \mu \mathrm{M}$ and $7 \mu \mathrm{M}$, AMP-PNP at final concentrations of $1 \mathrm{mM}$ and $2 \mathrm{mM}$, TRAM-34 at final concentrations of $20 \mu \mathrm{M}$ and $40 \mu \mathrm{M}$, and the respective DMSO control. After incubation for $1.5 \mathrm{~h}$ at $37{ }^{\circ} \mathrm{C}$ with $8 \% \mathrm{CO}_{2}$, cells were washed and fixed using $4 \%$ paraformaldehyde in $0.1 \mathrm{M}$ phosphatebuffered saline (PBS) for $15 \mathrm{~min}$. After permeabilization of cells, blocking of non-specific binding sites with blocking solution ( $1 \%$ BSA/PBS) for $1 \mathrm{~h}$ at $4{ }^{\circ} \mathrm{C}$ was performed followed by incubation with primary antibody mouse anti-HisTag antibody (BD Biosciences, Pharmingen, Germany) at a concentration of $1 \mu \mathrm{g} / \mathrm{ml}$ at $4{ }^{\circ} \mathrm{C}$ for $2 \mathrm{~h}$. For the control experiments, a 1:50 dilution of rabbit antiMMP14 antibody (Chemicon, CA, USA) and anti-FGF-2 (bFGF) (147): sc-79 antibody (Santa Cruz, CA, USA) was used. After rinsing with $\mathrm{PBS}$ for five times, cells were covered with a 1:30 dilution of the secondary antibody (FITC-conjugated polyclonal rabbit anti mouse immunoglobulin, (DakoCytomation, USA) and FITC-conjugated polyclonal swine anti-rabbit immunoglobulin (DAKO, Denmark)) in PBS at $4{ }^{\circ} \mathrm{C}$ for $1 \mathrm{~h}$. For a better illustration of the cell, border cells were simultaneously stained for actin with phalloidin rhodamine dye (Biotium, USA) according to the manufacture's instructions. Afterwards, cells were washed with PBS and coverslips were mounted on slides using Hard Set Mounting Medium with DAPI (Vectashield, H-1500, Linearis, Germany) and imaged using an Axio Imager Zeiss Z1 fluorescence microscope (Axiovision Rel. 4.6.3) equipped with an Axio Cam MR camera. Images were taken using $63 \times$ oil immersion lenses.

\section{Electrophysiological recordings}

Potassium currents were recorded at room temperature in the whole-cell configuration, using an EPC9 patch clamp amplifier (HEKA Elektronik, Germany) controlled with PatchMaster software (HEKA Elektronik). In all experiments, the holding potential was $-80 \mathrm{mV}$. Series-resistance errors were compensated in the range of $70-90 \%$. Patch pipettes were fabricated from Kimax-51 glass (Kimble Glass, USA) with resistance values in the range of 0.8-1.5 M $\Omega$. Off-line analysis of data was performed using IgorPro (WaveMetrics, USA) and FitMaster (HEKA Elektronik). The internal solution contained $130 \mathrm{mM} \mathrm{KCl}, 2 \mathrm{mM} \mathrm{MgCl}, 10 \mathrm{mM}$ EGTA, $10 \mathrm{mM}$ Hepes and $9.3 \mathrm{mM} \mathrm{CaCl}$ to yield $1 \mu \mathrm{M}$ free $\mathrm{Ca}^{2+}$; $\mathrm{pH}$ was adjusted to 7.4 with $\mathrm{KOH}$. The standard bath solution contained $5 \mathrm{mM} \mathrm{KCl}, 155 \mathrm{mM} \mathrm{NaCl}, 2 \mathrm{mM} \mathrm{CaCl}_{2}$ and $10 \mathrm{mM}$ Hepes; $\mathrm{pH}$ was adjusted to 7.4 with $\mathrm{NaOH}$. Currents were elicited by 500 $\mathrm{ms}$ voltage ramps, ranging from $-100 \mathrm{mV}$ to $+50 \mathrm{mV}$. In block experiments with TRAM-34 the same ramp protocol was applied every $5 \mathrm{~s}$. Mean current densities were determined between -40 $\mathrm{mV}$ and $-25 \mathrm{mV}$. Current recordings on transfected HEK293 cells were performed 1-3 days after transfection.

\section{Calcium measurements}

Cells in culture medium were loaded with $4 \mu \mathrm{M}$ Fura-2-AM (Invitrogen) in DMEM for about 40 min at $37{ }^{\circ} \mathrm{C}$. During recording at room temperature, cells were continuously perfused with HBSS solution containing $142 \mathrm{mM} \mathrm{NaCl}, 5.6 \mathrm{mM} \mathrm{KCl}, 1 \mathrm{mM}$ $\mathrm{MgCl}_{2}, 2 \mathrm{mM} \mathrm{CaCl}_{2}, 0.34 \mathrm{mM} \mathrm{Na} \mathrm{HPO}_{4}, 0.44 \mathrm{mM} \mathrm{KH} \mathrm{KO}_{4}, 4.2$ $\mathrm{mM} \mathrm{NaHCO}, 10 \mathrm{mM} \mathrm{HEPES}$, and $5.6 \mathrm{mM}$ glucose, at a flow rate of $3 \mathrm{ml} / \mathrm{min}$ in a chamber with $2 \mathrm{ml}$ volume. Fluorescence measurements were performed with a combination of a scanning monochromator and a photomultiplier (Polychrome II, TILL Photonics, Gräfelfing, Germany), mounted on an inverted microscope (Axiovert 100, Carl Zeiss, Jena, Germany) with a $20 \times$ objective (Neofluar, Carl Zeiss). Cells were illuminated alternately at 340 $\mathrm{nm}$ or $380 \mathrm{~nm}$ and light of about $510 \mathrm{~nm}$ was collected with a cooled CCD camera (IMAGO, pco, Kelheim, Germany). TILLvisION (TILL Photonics) software was used for data analysis. The $340 \mathrm{~nm} / 380 \mathrm{~nm}$ ratio of the background-corrected fluorescence signal was used to calculate the free intracellular calcium concentration according to Neher et al. [72], presuming a $\mathrm{K}_{\mathrm{D}}$ of $220 \mathrm{nM}$ and alpha 0.1 [57]. The calibration constants $R_{\min }$ and $R_{\max }$ were determined in vivo using solutions with zero calcium or $90 \mu \mathrm{M}$ free calcium to fill cells in the whole cell patch-clamp configuration. A sample rate of $0.1 \mathrm{~Hz}$ was used in HEK293 cell experiments. In channel block experiments, TRAM-34 $(10 \mu \mathrm{M})$ was applied via a glass pipette in the direct vicinity of the cells and the fluorescence was recorded with sample rates of 0.02 or $0.05 \mathrm{~Hz}$.

\section{Statistical analysis}

In the bar graphs, results are expressed as mean \pm s.d. (range) or percent. Comparison between groups was made using the Student's unpaired $t$-test. A $P$-value $<0.05$ was considered as statistically significant (ns: not significant, $*: P<0.05$, **: $P<0.01$, ***: $P<0.001$ ). All calculations were made using the GraphPad Prism Software (GraphPad Software, Inc., San Diego, USA).

\section{Acknowledgments}

We are indebted to Dr J Johnson (University of Munich, Germany) for providing the melanoma cell lines, Mel Im and Mel Ju, and to Dr B Distel (University of Amsterdam, Netherlands) for providing the Sarlp (H79G) vector. We also thank Dr A Schwab (University of Muenster, Germany) for the generous donation of the expression vector of the KCa3.1 channel and Dr C Voelker (University of Bonn, Germany) for the Golgi-GFP (endomannosidase) plasmid. This work was supported by grants from the DFG and the German Cancer Aid (Melanoma Research Network).

\section{References}

1 Bosserhoff AK, Kaufmann M, Kaluza B, et al. Melanomainhibiting activity, a novel serum marker for progression of malignant melanoma. Cancer Res 1997; 57:3149-3153.

2 Bosserhoff AK, Stoll R, Sleeman JP, et al. Active detachment involves inhibition of cell-matrix contacts of malignant melanoma cells by secretion of melanoma inhibitory activity. Lab Invest 2003; 83:1583-1594.

3 Poser I, Tatzel J, Kuphal S, Bosserhoff AK. Functional role 
of MIA in melanocytes and early development of melanoma. Oncogene 2004; 23:6115-6124.

4 Bosserhoff AK, Lederer M, Kaufmann M, et al. MIA, a novel serum marker for progression of malignant melanoma. Anticancer Res 1999; 19:2691-2693.

5 Dreau D, Bosserhoff AK, White RL, Buettner R, Holder WD. Melanoma-inhibitory activity protein concentrations in blood of melanoma patients treated with immunotherapy. Oncol Res 1999; 11:55-61.

6 Stahlecker J, Gauger A, Bosserhoff A, et al. MIA as a reliable tumor marker in the serum of patients with malignant melanoma. Anticancer Res 2000; 20:5041-5044.

7 Bauer R, Humphries M, Fassler R, et al. Regulation of integrin activity by MIA. J Biol Chem 2006; 281:11669-11677.

8 Schmidt J, Bosserhoff AK. Processing of MIA protein during melanoma cell migration. Int J Cancer 2009.

9 Blesch A, Bosserhoff AK, Apfel R, et al. Cloning of a novel malignant melanoma-derived growth-regulatory protein, MIA. Cancer Res 1994; 54:5695-5701.

10 Rabouille C, Klumperman J. Opinion: the maturing role of COPI vesicles in intra-Golgi transport. Nat Rev Mol Cell Biol 2005; 6:812-817.

11 Jena BP. Membrane fusion: role of SNAREs and calcium. Protein Pept Lett 2009; 16:712-717.

12 Komuro H, Kumada T. Ca2+ transients control CNS neuronal migration. Cell Calcium 2005; 37:387-393.

13 Pettit EJ, Fay FS. Cytosolic free calcium and the cytoskeleton in the control of leukocyte chemotaxis. Physiol Rev 1998; 78:949-967.

14 Brundage RA, Fogarty KE, Tuft RA, Fay FS. Calcium gradients underlying polarization and chemotaxis of eosinophils. Science 1991; 254:703-706.

15 Hahn K, DeBiasio R, Taylor DL. Patterns of elevated free calcium and calmodulin activation in living cells. Nature 1992; 359:736-738.

16 Schwab A, Wojnowski L, Gabriel K, Oberleithner H. Oscillating activity of a $\mathrm{Ca}(2+)$-sensitive $\mathrm{K}+$ channel. A prerequisite for migration of transformed Madin-Darby canine kidney focus cells. J Clin Invest 1994; 93:1631-1636.

17 Franco SJ, Huttenlocher A. Regulating cell migration: calpains make the cut. $J$ Cell Sci 2005; 118:3829-3838.

18 Jager H, Dreker T, Buck A, et al. Blockage of intermediateconductance $\mathrm{Ca} 2+$-activated $\mathrm{K}+$ channels inhibit human pancreatic cancer cell growth in vitro. Mol Pharmacol 2004; 65:630-638.

19 Tajima N, Schonherr K, Niedling S, et al. Ca2+-activated K+ channels in human melanoma cells are up-regulated by hypoxia involving hypoxia-inducible factor-1alpha and the von Hippel-Lindau protein. J Physiol 2006; 571:349-359.

20 Wang J, Xu YQ, Liang YY, et al. An intermediate-conductance $\mathrm{Ca}(2+)$-activated $\mathrm{K}(+)$ channel mediates B lymphoma cell cycle progression induced by serum. Pflugers Arch 2007; 454:945-956.

21 Lallet-Daher H, Roudbaraki M, Bavencoffe A, et al. Intermediate-conductance $\mathrm{Ca} 2+$-activated $\mathrm{K}+$ channels (IKCa1) regulate human prostate cancer cell proliferation through a close control of calcium entry. Oncogene 2009; 28:1792-1806.

22 Schwab A, Gabriel K, Finsterwalder F, et al. Polarized ion transport during migration of transformed Madin-Darby ca- nine kidney cells. Pflugers Arch 1995; 430:802-807.

23 Schwab A, Reinhardt J, Schneider SW, Gassner B, Schuricht B. $\mathrm{K}(+)$ channel-dependent migration of fibroblasts and human melanoma cells. Cell Physiol Biochem 1999; 9:126-132.

24 Cruse G, Duffy SM, Brightling CE, Bradding P. Functional $\mathrm{KCa} 3.1 \mathrm{~K}+$ channels are required for human lung mast cell migration. Thorax 2006; 61:880-885.

25 Kessler W, Budde T, Gekle M, Fabian A, Schwab A. Activation of cell migration with fibroblast growth factor-2 requires calcium-sensitive potassium channels. Pflugers Arch 2008; 456:813-823.

26 Palazzo AF, Joseph HL, Chen YJ, et al. Cdc42, dynein, and dynactin regulate MTOC reorientation independent of Rhoregulated microtubule stabilization. Curr Biol 2001; 11:15361541.

27 Nebenfuhr A, Ritzenthaler C, Robinson DG. Brefeldin A: deciphering an enigmatic inhibitor of secretion. Plant Physiol 2002; 130:1102-1108.

28 Iida J, Wilhelmson KL, Price MA, et al. Membrane type-1 matrix metalloproteinase promotes human melanoma invasion and growth. J Invest Dermatol 2004; 122:167-176.

29 Mori H, Tomari T, Koshikawa N, et al. CD44 directs membrane-type 1 matrix metalloproteinase to lamellipodia by associating with its hemopexin-like domain. EMBO J 2002; 21:3949-3959.

30 Nugent MA, Iozzo RV. Fibroblast growth factor-2. Int J Biochem Cell Biol 2000; 32:115-120.

31 Nickel W. Unconventional secretory routes: direct protein export across the plasma membrane of mammalian cells. Traffic 2005; 6:607-614.

32 Aridor M, Bannykh SI, Rowe T, Balch WE. Sequential coupling between COPII and COPI vesicle coats in endoplasmic reticulum to Golgi transport. J Cell Biol 1995; 131:875-893.

33 Barlowe C, Orci L, Yeung T, et al. COPII: a membrane coat formed by Sec proteins that drive vesicle budding from the endoplasmic reticulum. Cell 1994; 77:895-907.

34 Kuge O, Kuge S. [COP-coated vesicles in intracellular protein transport]. Tanpakushitsu Kakusan Koso 1995; 40:2427-2435.

35 Gaynor EC, Graham TR, Emr SD. COPI in ER/Golgi and intra-Golgi transport: do yeast COPI mutants point the way? Biochim Biophys Acta 1998; 1404:33-51.

36 Hachiya NS, Watanabe K, Yamada M, Sakasegawa Y, Kaneko $\mathrm{K}$. Anterograde and retrograde intracellular trafficking of fluorescent cellular prion protein. Biochem Biophys Res Commun 2004; 315:802-807.

37 Schwab A. Function and spatial distribution of ion channels and transporters in cell migration. Am J Physiol Renal Physiol 2001; 280:F739-F747.

38 Ghanshani S, Wulff H, Miller MJ, et al. Up-regulation of the IKCa1 potassium channel during T-cell activation. Molecular mechanism and functional consequences. J Biol Chem 2000; 275:37137-37149.

39 Barfod ET, Moore AL, Roe MW, Lidofsky SD. Ca2+-activated IK1 channels associate with lipid rafts upon cell swelling and mediate volume recovery. J Biol Chem 2007; 282:89848993.

40 Strayer DS, Hoek JB, Thomas AP, White MK. Cellular activation by $\mathrm{Ca} 2+$ release from stores in the endoplasmic reticulum but not by increased free $\mathrm{Ca} 2+$ in the cytosol. Biochem $\mathrm{J}$ 
1999; 344 Pt 1:39-46.

41 Kauffman RF, Taylor RW, Pfeiffer DR. Cation transport and specificity of ionomycin. Comparison with ionophore A23187 in rat liver mitochondria. J Biol Chem 1980; 255:2735-2739.

42 Ridley AJ, Schwartz MA, Burridge K, et al. Cell migration: integrating signals from front to back. Science 2003; 302:1704-1709.

43 Vicente-Manzanares M, Webb DJ, Horwitz AR. Cell migration at a glance. J Cell Sci 2005; 118:4917-4919.

44 Borregaard N, Lollike K, Kjeldsen L, et al. Human neutrophil granules and secretory vesicles. Eur J Haematol 1993; 51:187-198.

45 Jamur MC, Vugman I, Hand AR. Ultrastructural and cytochemical studies of acid phosphatase and trimetaphosphatase in rat peritoneal mast cells developing in vivo. Cell Tissue Res 1986; 244:557-563.

46 Burkhardt JK, Hester S, Lapham CK, Argon Y. The lytic granules of natural killer cells are dual-function organelles combining secretory and pre-lysosomal compartments. J Cell Biol 1990; 111:2327-2340.

47 Peters PJ, Borst J, Oorschot V, et al. Cytotoxic T lymphocyte granules are secretory lysosomes, containing both perforin and granzymes. J Exp Med 1991; 173:1099-1109.

48 Bennett MK. Ca2+ and the regulation of neurotransmitter secretion. Curr Opin Neurobiol 1997; 7:316-322.

49 Greengard P, Valtorta F, Czernik AJ, Benfenati F. Synaptic vesicle phosphoproteins and regulation of synaptic function. Science 1993; 259:780-785.

50 Kato M, Sasaki T, Ohya T, et al. Physical and functional interaction of rabphilin-3A with alpha-actinin. J Biol Chem 1996; 271:31775-31778.

51 Miyazaki M, Shirataki H, Kohno H, et al. Identification as beta-adducin of a protein interacting with rabphilin-3A in the presence of $\mathrm{Ca} 2+$ and phosphatidylserine. Biochem Biophys Res Commun 1994; 205:460-466.

52 Weis S, Schneggenburger R, Neher E. Properties of a model of $\mathrm{Ca}(++)$-dependent vesicle pool dynamics and short term synaptic depression. Biophys J 1999; 77:2418-2429.

53 Saadoun S, Papadopoulos MC, Hara-Chikuma M, Verkman AS. Impairment of angiogenesis and cell migration by targeted aquaporin-1 gene disruption. Nature 2005; 434:786-792.

54 Stock C, Schwab A. Role of the $\mathrm{Na} / \mathrm{H}$ exchanger NHE1 in cell migration. Acta Physiol (Oxf) 2006; 187:149-157.

55 Lawson MA, Maxfield FR. $\mathrm{Ca}(2+)$ - and calcineurin-dependent recycling of an integrin to the front of migrating neutrophils. Nature 1995; 377:75-79.

56 Yang S, Huang XY. Ca2+ influx through L-type Ca2+ channels controls the trailing tail contraction in growth factorinduced fibroblast cell migration. J Biol Chem 2005; 280:27130-27137.

57 Meyer R, Schonherr R, Gavrilova-Ruch O, Wohlrab W, Heinemann SH. Identification of ether a go-go and calcium-activated potassium channels in human melanoma cells. J Membr Biol 1999; 171:107-115.
58 Aiyar J. Potassium channels in leukocytes and toxins that block them: structure, function and therapeutic implications. Pererspect Drug Discov Des 1999; 15/16:257-280.

59 Eder C. Ion channels in microglia (brain macrophages). Am J Physiol 1998; 275:C327-C342.

60 Kohler R, Wulff H, Eichler I, et al. Blockade of the intermediate-conductance calcium-activated potassium channel as a new therapeutic strategy for restenosis. Circulation 2003; 108:1119-1125.

61 Ouadid-Ahidouch H, Roudbaraki M, Delcourt P, et al. Functional and molecular identification of intermediate-conductance $\mathrm{Ca}(2+)$-activated $\mathrm{K}(+)$ channels in breast cancer cells: association with cell cycle progression. Am J Physiol Cell Physiol 2004; 287:C125-C134.

62 Parihar AS, Coghlan MJ, Gopalakrishnan M, Shieh CC. Effects of intermediate-conductance $\mathrm{Ca} 2+$-activated $\mathrm{K}+$ channel modulators on human prostate cancer cell proliferation. Eur J Pharmacol 2003; 471:157-164.

63 Schwab A, Westphale HJ, Wojnowski L, Wunsch S, Oberleithner $\mathrm{H}$. Spontaneously oscillating $\mathrm{K}+$ channel activity in transformed Madin-Darby canine kidney cells. J Clin Invest 1993; 92:218-223.

64 Jin M, Defoe DM, Wondergem R. Hepatocyte growth factor/ scatter factor stimulates $\mathrm{Ca} 2+$-activated membrane $\mathrm{K}+$ current and migration of MDCK II cells. J Membr Biol 2003; 191:7786.

65 Schilling T, Stock C, Schwab A, Eder C. Functional importance of $\mathrm{Ca} 2+$-activated $\mathrm{K}+$ channels for lysophosphatidic acid-induced microglial migration. Eur J Neurosci 2004; 19:1469-1474.

66 Schwab A, Wulf A, Schulz C, et al. Subcellular distribution of calcium-sensitive potassium channels (IK1) in migrating cells. J Cell Physiol 2006; 206:86-94.

67 Schwab A, Schuricht B, Seeger P, Reinhardt J, Dartsch PC. Migration of transformed renal epithelial cells is regulated by $\mathrm{K}+$ channel modulation of actin cytoskeleton and cell volume. Pflugers Arch 1999; 438:330-337.

68 Rao JN, Platoshyn O, Li L, et al. Activation of $\mathrm{K}(+)$ channels and increased migration of differentiated intestinal epithelial cells after wounding. Am J Physiol Cell Physiol 2002; 282:C885-C898.

69 Feinshreiber L, Singer-Lahat D, Ashery U, Lotan I. Voltagegated potassium channel as a facilitator of exocytosis. Ann $\mathrm{N}$ $Y$ Acad Sci 2009; 1152:87-92.

70 Ho SN, Hunt HD, Horton RM, Pullen JK, Pease LR. Site-directed mutagenesis by overlap extension using the polymerase chain reaction. Gene 1989; 77:51-59.

71 Tatzel J, Poser I, Schroeder J, Bosserhoff AK. Inhibition of melanoma inhibitory activity (MIA) expression in melanoma cells leads to molecular and phenotypic changes. Pigment Cell Res 2005; 18:92-101.

72 Neher E. The use of fura-2 for estimating $\mathrm{Ca}$ buffers and $\mathrm{Ca}$ fluxes. Neuropharmacology 1995; 34:1423-1442.

(Supplementary information is linked to the online version of the paper on the Cell Research website.) 